\title{
Isobaric tags for relative and absolute quantification-based proteomic analysis of testis biopsies in rhesus monkeys treated with transient scrotal hyperthermia
}

\author{
Meng Rao ${ }^{1,2, *}$, Sha $\mathrm{Ma}^{3, *}$, Shifu Hu${ }^{1}$, Hui Lei ${ }^{1}$, Yanqing Wu ${ }^{1}$, Yanfei Zhou ${ }^{4}$, Wei Xia ${ }^{1,5}$ \\ and Changhong Zhu $\mathbf{u}^{1,5}$ \\ ${ }^{1}$ Family Planning Research Institute, Tongji Medical College, Huazhong University of Science and Technology, Wuhan, China \\ ${ }^{2}$ Department of Reproduction and Genetics, The First Affiliated Hospital of Kunming Medical University, Kunming, China \\ ${ }^{3}$ Wuhan Women and Children's Health Care Center of Hubei Province, Wuhan, China \\ ${ }^{4}$ Changsha Hospital for Maternal and Child Health Care, Changsha, China \\ ${ }^{5}$ Reproductive Medicine Center, Tongji Medical College, Huazhong University of Science and Technology, Wuhan, China \\ *These authors have contributed equally to this work \\ Correspondence to: Wei Xia, email: tjxiawei@hust.edu.cn \\ Yanfei Zhou, email: 291808975@qq.com \\ Keywords: heat stress, spermatogenesis, rhesus monkeys, iTRAQ, proteomics \\ Received: April 26, $2017 \quad$ Accepted: July 29, $2017 \quad$ Published: September 08, 2017 \\ Copyright: Rao et al. This is an open-access article distributed under the terms of the Creative Commons Attribution License 3.0 \\ (CC BY 3.0), which permits unrestricted use, distribution, and reproduction in any medium, provided the original author and source \\ are credited.
}

\section{ABSTRACT}

This study aimed to examine the cellular and molecular events that occur in rhesus monkey testes after scrotal hyperthermia. Eight male adult rhesus monkeys were subjected to scrotal hyperthermia at $43^{\circ} \mathrm{C}$ for $30 \mathrm{~min}$ daily for 6 consecutive days. Sperm concentration, reproductive hormones, and testis histology were examined before hyperthermia (day 0 ), and at 8, 15, 30, 45, 60, 75, and 90 days after the initiation of hyperthermia. iTRAQ-based proteomic analysis was conducted on testicular tissues collected on days 0,8 , and 60 to identify differentially expressed proteins at the early and recovery stages of testicular damage. The sperm concentration was significantly decreased at days 30 and 45 after treatment $(p<$ 0.01 ) and recovered to baseline at day 60 . When compared with day 0,101 and 24 differentially expressed proteins were identified at days 8 and 60 after heat treatment, respectively. The molecular functions of the differentially expressed proteins at day 8 were mainly nucleic acid binding, unfolded protein binding, nucleotide binding, and nucleoside phosphate binding. Spliceosome was enriched as the most significant pathway at day 8. CIRBP, PSIP1, Sam68, and Decorin were validated and found to be consistent with the proteomic data, indicating the reliability of the proteomic profiles identified in this study. In summary, we suggest that the proteins identified in this study may play important roles in heat-induced spermatogenic impairment. Some of these proteins, such as CIRBP, PSIP1, Sam68, and Decorin, may be early molecular targets responsible for spermatogenesis suppression induced by heat treatment.

\section{INTRODUCTION}

In most mammals, including humans, the testes are located in the scrotum outside the main body cavity to maintain a lower-temperature environment for normal spermatogenesis [1]. However, the testicular thermoregulation balance can be disrupted by several endogenous and exogenous factors. Cryptorchidism and varicocele are the main endogenous factors that lead to testicular hyperthermia and affect normal spermatogenesis $[2,3]$. Scrotal heat stress from occupational exposure to high environmental temperatures, such as that experienced 
by welders and drivers, can have a deleterious effect on spermatogenesis $[4,5]$.

Hot tubs are popular in China and can be enjoyed in various places, including hotels, holiday resorts, scenic spots, and even at home [6]. Most hot tub enthusiasts are attracted by commercial advertisements that exaggerate the health effects of hot tubs, with no concern for the potential damage to reproduction. The temperature in a hot tub generally varies from $37^{\circ} \mathrm{C}$ to $45^{\circ} \mathrm{C}$, which is much higher than the normal scrotal temperature. In our previous clinical study, we simulated a hot tub environment and exposed healthy adult volunteers to scrotal hyperthermia at $43^{\circ} \mathrm{C}$ ten times for $30 \mathrm{~min}$ each, once daily or once every 3 days [6, 7]. We found an obvious decrease in sperm concentration, total sperm count, sperm motility, and sperm function after scrotal hyperthermia. Sperm DNA integrity was also severely damaged $[6,7]$. Studies have indicated that heat stress-induced spermatogenic impairment is mainly due to mitochondria-dependent germ cell apoptosis $[6,8,9]$. Nevertheless, the complicated process of apoptosis is regulated by many factors, and the molecular mechanisms that underlie this process are still largely unknown.

Rocha et al. [10] investigated the effect of testicular hyperthermia on ram semen plasma proteome using twodimensional SDS-PAGE and mass spectrometry (2DEMS) and found a series of protein targets involved in sperm protection, maturation, and fertilization. Another two studies have revealed the molecular mechanism of heat-induced spermatogenic impairment in mouse and human testes, respectively $[11,12]$. Both studies were based on 2DE-MS techniques, which are less sensitive and less effective than the isobaric tags for relative and absolute quantification (iTRAQ) -based proteomic method for identifying specific proteins, very small or large proteins, proteins expressed at very low levels, and membrane proteins [13, 14]. In current proteomics research, the method used to quantify proteins has developed into a combination of ITRAQ and liquid chromatography-tandem mass spectrometry (LCMS/MS) [15]. iTRAQ has relatively high throughput and simultaneously provides information on protein quantitation and identification $[13,14]$. The aim of this study was to use iTRAQ proteomic technology to analyze the proteins expressed in rhesus monkey testes at the early stage of spermatogenic damage and at the recovery stage after scrotal hyperthermia. Some key differentially expressed proteins and potential pathways were revealed for further study to clarify the underlying mechanisms involved in heat stress-induced spermatogenic impairment.

\section{RESULTS}

\section{Sperm parameters and reproductive hormone levels}

Semen from three monkeys was collected and examined. The sperm concentration before scrotal hyperthermia was $66.5 \pm 13.0 \times 10^{6} / \mathrm{ml}$. The concentration decreased obviously from day 15 after hyperthermia, reaching $0.5 \pm 0.3 \times 10^{6} / \mathrm{ml}$, approached 0 at days 30 and 45 (both $p<0.01$ when compared with baseline levels), and recovered to baseline at day $60\left(81.0 \pm 20.2 \times 10^{6} \%\right.$ $\mathrm{ml})$. Progressive sperm motility also showed an obvious decrease after hyperthermia and had recovered to baseline at day 60 after hyperthermia. This parameter was not analyzed at days 30 and 45 due to the extremely low sperm concentration. No obvious change was observed in total sperm motility among these observation time points, as shown in Figure $1 \mathrm{~A}-1 \mathrm{C}$. The serum FSH, LH, and TT levels are presented in Figure 1D-1F. No significant differences were observed in the levels before and after heat treatment.

\section{Testicular histology}

Testicular histology was examined after HE staining. The results are presented in Figure 2. The structure of seminiferous epithelium was disrupted at day 8 after hyperthermia with some germ cell sloughing from Sertoli cells. There were also some mature spermatozoa in the lumen during this period, whereas no obvious change was observed in the interstitial space. At days 15 and 30 after treatment, most germ cells had been lost from the seminiferous epithelium, and no obvious change was seen in the Sertoli cells. The structure of the seminiferous epithelium started to recover between days 45 and 75 and had completely recovered to normal by day 90 . We analyzed the diameter of seminiferous tubules and the thickness of germinal epithelium, the results showed that the tubule diameter decreased significantly at day 15,30 and 45 (all $p<0.01$ ) and tended to recover at day 60. The thickness of seminiferous tubules decreased significantly at day $15,30,45$ and 60 (all $p<0.01$ ), and totally recovered to baseline at day 75 .

\section{Identification and quantification of differentially expressed proteins}

In total, 5319 proteins were detected by proteome analysis, 3769 of which were trusted proteins when taking FDR $<1 \%$ and matched peptides $>1$ as the standard. After quantitatively comparing the proteome profiles of the testes samples collected at different time points, we found that 101 proteins were expressed differentially before treatment and day 8 after treatment, of which 35 were up-regulated $(>1.5$-fold change, $p<0.05)$ and 66 were down-regulated $(<0.67$-fold change, $p<0.05)$. There were also 24 proteins that were expressed differentially before treatment and day 60 after treatment, of which 23 were upregulated and one was down-regulated, as shown in Table 1. Detailed information about the differentially expressed proteins identified at days 8 and 60 is presented in Tables 2 and 3, respectively. 


\section{Gene ontology of differentially expressed proteins}

Gene ontology (GO) analysis was conducted to understand the functional basis of the differentially expressed proteins identified by iTRAQ. Enrichment analysis using the hypergeometric test is used to test whether a GO term is statistically enriched for a given set of genes. The biological process, cell component and molecular function data was the basic information of GO analysis. A total of 113 and 88 biological processes were enriched $(p<0.05)$ for the differentially expressed proteins of day 0 vs day 8 and day 0 vs day 60 , respectively. The top 10 enriched processes are shown in Figure 3A and 3B. Most of the proteins that differed between day 0 and day 8 were those primarily involved in sexual reproduction, fertilization, and gamete generation. The proteins that differed between day 0 and day 60 were mainly those involved in sexual reproduction, gamete generation, and macromolecular complex subunits. There were 23 and 19 cell components enriched $(p<0.05)$ for the differentially expressed proteins of day 0 vs day 8 and day 0 vs day 60 , respectively. The top 10 enriched processes are shown in Figure $3 \mathrm{C}$ and 3D. In the molecular function analysis, 30 and 19 processes were enriched for the differentially expressed proteins of day 0 vs day 8 and day 0 vs day 60 , respectively. The top 10 enriched processes are shown in Figure $3 \mathrm{E}$ and $3 \mathrm{~F}$.

\section{KEGG pathway and protein-protein interaction analysis}

Kyoto Encyclopedia of Genes and Genomes (KEGG) pathway analysis was conducted to enrich the potential pathways of the identified proteins with differential expression. A total of 14 and 5 pathways ( $p$ $<0.05)$ were enriched for the differentially expressed proteins of day 0 vs day 8 and day 0 vs day 60 , respectively, as shown in Tables 4 and 5. The spliceosome was the most significant KEGG pathway for the altered proteins of day 0 vs day 8 , with seven proteins (HNRNPA3, HSPA2, TRA2B, ALYREF, HNRNPC, SRSF2, and HNRNPK) involved. Protein-protein interaction (PPI) analysis was performed using the STRING (Search Tool for the Retrieval of Interacting Genes/Proteins) database. Supplementary Figure 1 show the PPI network combined with KEGG pathways for the differentially expressed proteins of day 0 vs day 8 and day 0 vs day 60 , respectively.

\section{Validation of iTRAQ data for selected candidate proteins}

The results of immunohistochemical analysis showed that PSIP1, CIRBP, Sam68, and decorin were expressed in both monkey and mouse testes, as shown in Figures 4 and 5. In untreated monkey and mouse
A
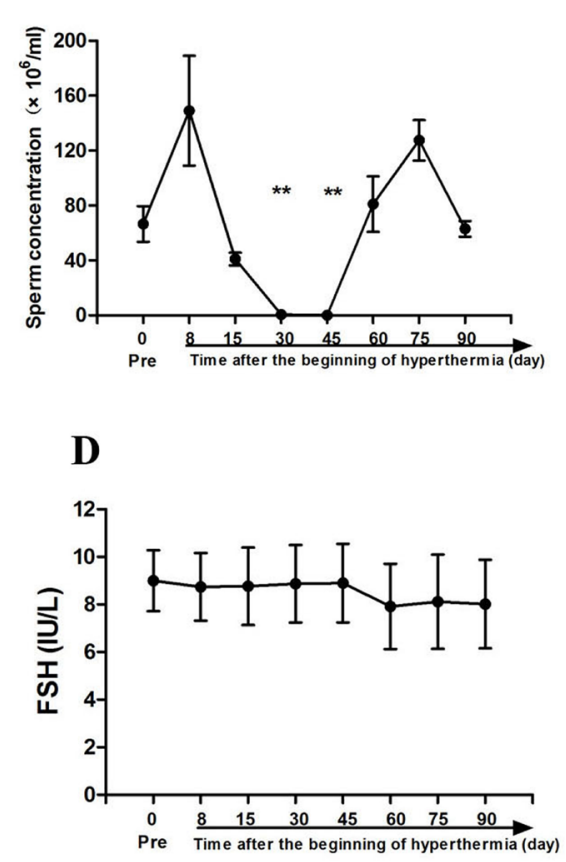

B

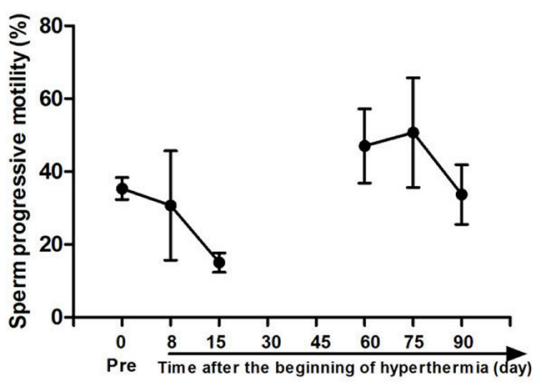

$\mathbf{E}$

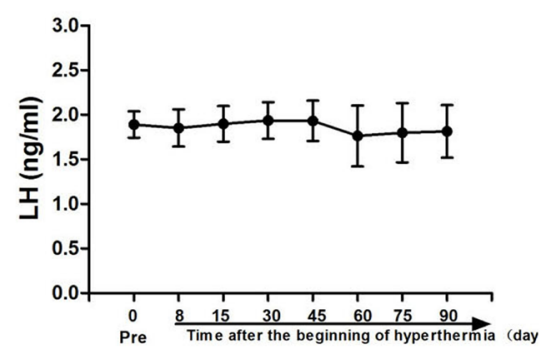

\section{C}
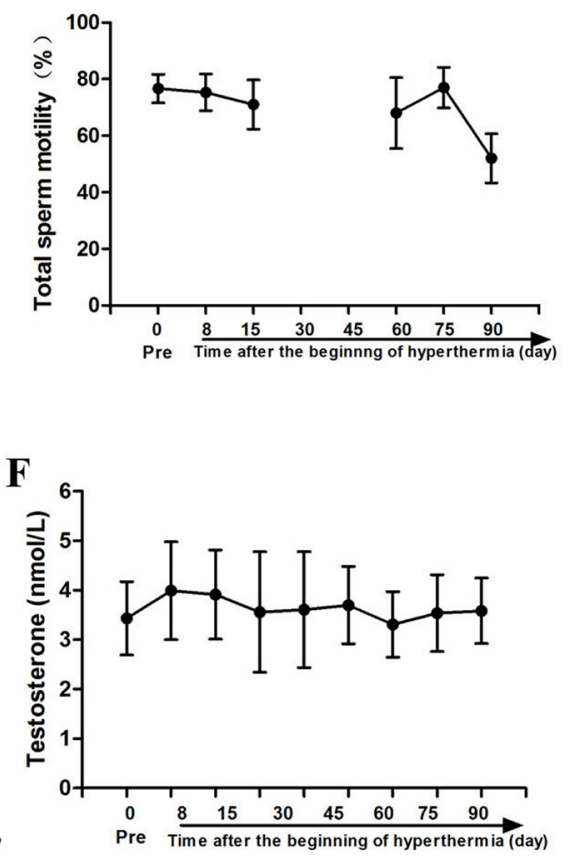

Figure 1: Sperm parameters and reproductive hormone levels before scrotal hyperthermia and at different time points after hyperthermia. (A) sperm concentration; (B) progressive sperm motility; (C) total sperm motility; (D, E and F) represent FSH, LH, and total testosterone levels, respectively. $\mathrm{N}=3$ for sperm parameter analysis; $\mathrm{N}=8$ for reproductive hormone test. 
testes, a high nuclear expression of CIRBP was noted in the germ cells, mainly localized in spermatocytes and spermatogonia, without immunostaining in the Leydig cells or Sertoli cells. PSIP1 was also expressed in the nuclei of the germ cells and was mainly localized in spermatocytes and spermatids, with little or no immunostaining in the spermatogonia. Similarly, Sam68 was also highly expressed in the nuclei of spermatocytes and spermatids, and immunostaining was also detected in the nuclei of Leydig cells. All three proteins were downregulated after scrotal hyperthermia without any changes in the cellular localization. The expression level of decorin was very low in normal testes, but a higher expression profile was observed after heat treatment, when it was widely expressed in the cytoplasm of spermatocytes, spermatids, and Sertoli cells, with little staining in the spermatogonia in the monkey testes. However, the pattern of expression in the mouse testes was different from that in monkey testes, with some expression in the Leydig cells and Sertoli cells but little expression in the germ cells.

Western blotting analysis in the monkey testis was consistent with the iTRAQ results and immunohistochemical analysis. The relative expression levels of CIRBP, PSIP1, and Sam68 were significantly lower at day 8 after treatment than before treatment ( $p$ $=0.039,0.037$, and 0.043, respectively). Decorin was significantly up-regulated after heat treatment $(p=0.014)$, as shown in Figure 6.

\section{DISCUSSION}

To our knowledge, this is the first iTRAQ-based proteomic analysis on heat-induced spermatogenic impairment in non-human primates. We attempted to delineate the early testicular cell response to heat treatment and to elucidate the underlying molecular mechanism involved in heat-induced suppression of spermatogenesis.

Similar to our earlier study in humans [7], the suppression of spermatogenesis induced by heat stress was obvious and completely reversible in this study. The sperm concentrations of all three monkeys decreased obviously after heat treatment and exhibited severe oligozoospermia at days 30 and 45 after the first treatment. One of the monkeys even had azoospermia. This was consistent with another study in which monkeys were treated with the same intensity and frequency of scrotal hyperthermia [16]. The serum FSH, LH, and testosterone levels did not change throughout the experiment, indicating that circulating reproductive hormone levels were not affected by the transient heat stress. Our result is consistent with a study published by Lue et al. [17], in which monkeys' testicles were exposed to heat $\left(43^{\circ} \mathrm{C}\right.$ for $\left.30 \mathrm{~min}\right)$ for 2 consecutive days, which found that testosterone level was not changed after treatment. However, Hou et al. [18] carried out a study in which rats were exposed to a $40^{\circ} \mathrm{C}$ environment (whole body) for $2 \mathrm{~h}$ per day for 7 consecutive days and found that the serum testosterone concentration significantly decreased after treatment, perhaps as a result of damage to the hypothalamus. The different results may be due to differences in heat treatment strategies, duration, and species.

In this study, a total of 101 and 24 proteins were found to be significantly differentially expressed at days 8 and 60, respectively, when compared to baseline. KEGG pathway analysis enriched 14 and 5 potential pathways at days 8 and 60 , respectively. These pathways may be critical in the process of heat-induced spermatogenic impairment and the recovery process. Zhu et al. [11] also investigated differentially expressed proteins at

\section{A}

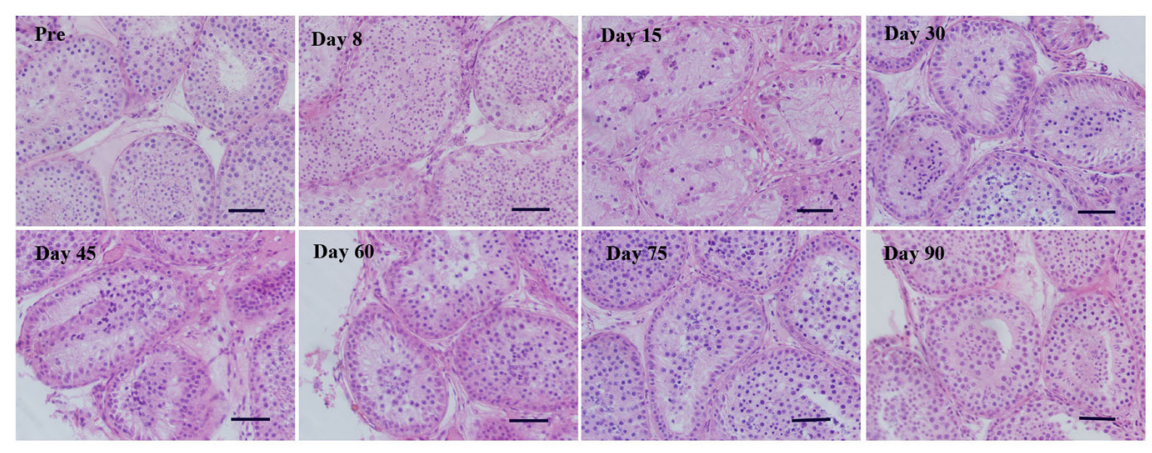

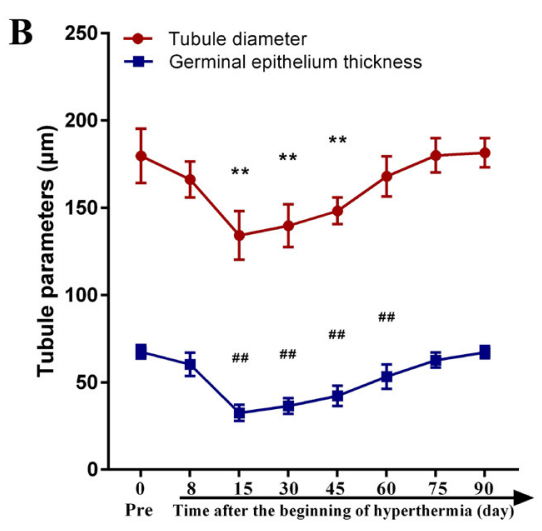

Figure 2: Testicular histology before scrotal hyperthermia and at different time points after hyperthermia. (A) representative pictures of testicular morphology; (B) quantitative analysis of the diameter of seminiferous tubules and the thickness of germinal epithelium. ${ }^{* *}, p<0.01$ when compared to baseline, for the diameter of seminiferous tubules; ${ }^{\#}, p<0.01$ when compared to baseline, for the thickness of germinal epithelium. Scale bar $=50 \mu \mathrm{m}$. For each time point, $\mathrm{n}=4$. 
Table 1: Identification of differentially expressed proteins in monkey testes after heat treatment

Day 8/pre-treatment

Day 60/pre-treatment

\begin{tabular}{lcc}
\hline No. of upregulated proteins & 35 & 23 \\
No. of downregulated proteins & 66 & 1 \\
Total number of differentially expressed proteins & 101 & 24 \\
\hline
\end{tabular}

Table 2: List of differentially expressed proteins on monkey testis collected at day 8 post-treatment compared with pre-treatment

\begin{tabular}{|c|c|c|c|c|}
\hline Protein & Gene & Peptides & Fold change & p-value \\
\hline Histone $\mathrm{H} 2 \mathrm{~B}$, testis & HIST1H2BA & 8 & 0.28 & 0.025 \\
\hline PREDICTED: y-box-binding protein 2-like & YBX2 & 13 & 0.38 & 0.000 \\
\hline $\begin{array}{l}\text { PREDICTED: KH domain-containing, RNA-binding, } \\
\text { signal transduction-associated protein 1-like }\end{array}$ & $\begin{array}{l}\text { KHDRBS1 } \\
\text { (Sam68) }\end{array}$ & 5 & 0.44 & 0.002 \\
\hline calmegin precursor & CLGN & 18 & 0.46 & 0.000 \\
\hline PREDICTED: hypothetical protein LOC701574 & HIST1H2AG & 15 & 0.48 & 0.000 \\
\hline PREDICTED: high mobility group protein B2-like & HMGB2 & 4 & 0.50 & 0.001 \\
\hline PC4 and SFRS1-interacting protein isoform 2 & PSIP1 & 7 & 0.50 & 0.000 \\
\hline heterogeneous nuclear ribonucleoprotein F & HNRNPF & 9 & 0.50 & 0.000 \\
\hline $\begin{array}{l}\text { RecName: Full=Histone H1t; AltName: Full=Testicular } \\
\text { H1 histone }\end{array}$ & HIST1H1T & 9 & 0.51 & 0.014 \\
\hline heat shock-related $70 \mathrm{kDa}$ protein 2 & HSPA2 & 59 & 0.52 & 0.000 \\
\hline Caltractin isoform 2 & CETN1 & 4 & 0.52 & 0.037 \\
\hline acylphosphatase- 1 isoform a & ACYP1 & 3 & 0.52 & 0.001 \\
\hline $\begin{array}{l}\text { PREDICTED: LOW QUALITY PROTEIN: } \\
\text { uncharacterized protein C1orf14-like }\end{array}$ & SHCBP1L & 10 & 0.53 & 0.000 \\
\hline L-lactate dehydrogenase $\mathrm{C}$ chain & LDHC & 16 & 0.54 & 0.000 \\
\hline ATP-dependent RNA helicase DDX39 & DDX39A & 15 & 0.55 & 0.001 \\
\hline $\begin{array}{l}\text { PREDICTED: heterogeneous nuclear ribonucleoprotein } \\
\text { A3-like isoform } 3\end{array}$ & HNRNPA3 & 18 & 0.55 & 0.000 \\
\hline prostaglandin E synthase 3 & PTGES3 & 7 & 0.56 & 0.004 \\
\hline PREDICTED: reticulocalbin-2 & $\mathrm{RCN} 2$ & 16 & 0.56 & 0.002 \\
\hline heterogeneous nuclear ribonucleoprotein $\mathrm{C}(\mathrm{C} 1 / \mathrm{C} 2)$ & LRRC46 & 21 & 0.57 & 0.000 \\
\hline hypothetical protein EGK_08462 & LRRC46 & 8 & 0.57 & 0.002 \\
\hline $\begin{array}{l}\text { heat shock protein } 90 \mathrm{kDa} \text { alpha (cytosolic), class A } \\
\text { member } 1\end{array}$ & HSP90AA1 & 66 & 0.57 & 0.000 \\
\hline GLIPR1-like protein 1 & GLIPR1L1 & 12 & 0.57 & 0.000 \\
\hline $40 \mathrm{~S}$ ribosomal protein $\mathrm{S} 7$ & RPS7 & 4 & 0.58 & 0.030 \\
\hline cold-inducible RNA-binding protein & CIRBP & 7 & 0.58 & 0.002 \\
\hline heterogeneous nuclear ribonucleoproteins A2/B1 & HNRNPA2B1 & 26 & 0.58 & 0.000 \\
\hline WD repeat-containing protein 62 isoform 1 & WDR62 & 4 & 0.58 & 0.010 \\
\hline calmodulin & CALM1 & 14 & 0.59 & 0.000 \\
\hline serine/arginine-rich splicing factor 2 & SRSF2 & 6 & 0.59 & 0.007 \\
\hline
\end{tabular}

(Continued) 


\begin{tabular}{|c|c|c|c|c|}
\hline Protein & Gene & Peptides & Fold change & p-value \\
\hline small ubiquitin-related modifier 2 isoform a precursor & SUMO2 & 2 & 0.59 & 0.003 \\
\hline hepatoma-derived growth factor-like protein 1 & HDGFL1 & 5 & 0.60 & 0.008 \\
\hline Histone H1d & HIST1H1D & 7 & 0.60 & 0.010 \\
\hline leucine zipper transcription factor-like protein 1 & LZTFL1 & 15 & 0.60 & 0.000 \\
\hline putative ATP-dependent RNA helicase DDX4 isoform 1 & DDX4 & 27 & 0.61 & 0.000 \\
\hline $\begin{array}{l}\text { PREDICTED: ecto-ADP-ribosyltransferase 3-like } \\
\text { isoform } 2\end{array}$ & ART3 & 9 & 0.61 & 0.004 \\
\hline hypothetical protein EGK_16207 & TKTL2 & 15 & 0.63 & 0.000 \\
\hline $\begin{array}{l}\text { PREDICTED: signal recognition particle } 14 \mathrm{kDa} \\
\text { protein-like }\end{array}$ & SRP14 & 2 & 0.63 & 0.030 \\
\hline uncharacterized protein LOC704570 & C6orf211 & 4 & 0.63 & 0.002 \\
\hline testis-expressed sequence 30 protein & TEX30 & 2 & 0.63 & 0.011 \\
\hline hypothetical protein EGK_02694 & BANF2 & 1 & 0.64 & 0.017 \\
\hline hypothetical protein EGK_10689 & TEX101 & 6 & 0.64 & 0.031 \\
\hline hypothetical protein EGK_04360 & PIWIL1 & 18 & 0.64 & 0.000 \\
\hline sperm surface protein $\mathrm{Sp} 17$ & SPA17 & 6 & 0.64 & 0.048 \\
\hline heterogeneous nuclear ribonucleoprotein $\mathrm{K}$ & HNRNPK & 29 & 0.64 & 0.000 \\
\hline 14-3-3 protein epsilon & YWHAE & 26 & 0.64 & 0.000 \\
\hline $60 \mathrm{~S}$ ribosomal protein $\mathrm{L} 23$ & RPL23 & 6 & 0.64 & 0.012 \\
\hline PREDICTED: ELAV-like protein 1 isoform 4 & ELAVL1 & 11 & 0.64 & 0.004 \\
\hline hypothetical protein EGK_04675, partial & PPIL3 & 2 & 0.64 & 0.019 \\
\hline Aly/REF export factor & ALYREF & 7 & 0.65 & 0.030 \\
\hline hypothetical protein EGK_03075 & ST13 & 11 & 0.65 & 0.001 \\
\hline transformer-2 protein homolog beta & TRA2B & 5 & 0.65 & 0.024 \\
\hline histone H2A.x & $\mathrm{H} 2 \mathrm{AFX}$ & 8 & 0.65 & 0.001 \\
\hline DAZ-associated protein 1 isoform $b$ & DAZAP1 & 9 & 0.65 & 0.000 \\
\hline hypothetical protein EGK_04363 & RAN & 6 & 0.66 & 0.010 \\
\hline L-lactate dehydrogenase A-like 6B & LDHAL6B & 9 & 0.66 & 0.047 \\
\hline T-complex protein 1 subunit zeta-2, partial & ССТ6В & 21 & 0.66 & 0.000 \\
\hline ruvB-like 1 & RUVBL1 & 13 & 0.66 & 0.001 \\
\hline peroxiredoxin-5, mitochondrial isoform a precursor & PRDX5 & 9 & 0.66 & 0.009 \\
\hline heat shock $70 \mathrm{kDa}$ protein $4 \mathrm{~L}$ & HSPA4L & 50 & 0.66 & 0.000 \\
\hline ATPase inhibitor, mitochondrial & ATPIF1 & 2 & 0.66 & 0.009 \\
\hline dr1-associated corepressor & DRAP1 & 1 & 0.66 & 0.011 \\
\hline peptidylprolyl isomerase $\mathrm{D}$ & PPID & 19 & 0.67 & 0.000 \\
\hline hypothetical protein LOC340277 isoform 1 & FAM221A & 4 & 0.67 & 0.005 \\
\hline glutathione S-transferase M3 & GSTM3 & 31 & 0.67 & 0.000 \\
\hline X-ray repair cross-complementing protein 6 & XRCC6 & 25 & 0.67 & 0.000 \\
\hline hypothetical protein EGK_12573 & $44 \mathrm{M} 2.3$ & 7 & 0.67 & 0.006 \\
\hline Ubiquilin-3 & UBQLN3 & 2 & 0.67 & 0.042 \\
\hline epoxide hydrolase 1 & EPHX1 & 13 & 1.50 & 0.000 \\
\hline
\end{tabular}

(Continued) 


\begin{tabular}{|c|c|c|c|c|}
\hline Protein & Gene & Peptides & Fold change & p-value \\
\hline $\begin{array}{l}\text { tubulointerstitial nephritis antigen-like isoform } 1 \\
\text { precursor }\end{array}$ & TINAGL1 & 7 & 1.50 & 0.028 \\
\hline PREDICTED: complement component C9 & C9 & 6 & 1.51 & 0.000 \\
\hline RAC-alpha serine/threonine-protein kinase & AKT1 & 2 & 1.51 & 0.048 \\
\hline guanine nucleotide-binding protein $\mathrm{G}(\mathrm{q})$ subunit alpha & GNAQ & 4 & 1.53 & 0.046 \\
\hline dipeptidase 1 precursor & DPEP1 & 9 & 1.54 & 0.028 \\
\hline tropomyosin beta chain isoform 2 & TPM2 & 20 & 1.56 & 0.000 \\
\hline thioredoxin & TXN & 6 & 1.57 & 0.021 \\
\hline beta-hexosaminidase subunit alpha precursor & HEXA & 4 & 1.59 & 0.049 \\
\hline Plectin & PLEC & 107 & 1.60 & 0.012 \\
\hline $\begin{array}{l}\mathrm{N} \text {-acylethanolamine-hydrolyzing acid amidase isoform } \\
1 \text { precursor }\end{array}$ & NAAA & 4 & 1.60 & 0.032 \\
\hline decorin isoform a preproprotein & $\mathrm{DCN}$ & 13 & 1.61 & 0.001 \\
\hline PREDICTED: tropomyosin alpha-4 chain isoform 9 & TPM1 & 26 & 1.61 & 0.003 \\
\hline immunoglobulin heavy chain & IGHG1 & 20 & 1.61 & 0.000 \\
\hline Olfactomedin-like protein 1 & OLFML1 & 8 & 1.62 & 0.001 \\
\hline PREDICTED: annexin A1 isoform 4 & ANXA1 & 18 & 1.66 & 0.000 \\
\hline plastin-2 & LCP1 & 7 & 1.67 & 0.002 \\
\hline adenosine kinase isoform $b$ & ADK & 6 & 1.69 & 0.036 \\
\hline keratin, type II cytoskeletal 8 & KRT8 & 13 & 1.71 & 0.002 \\
\hline Angiotensin-converting enzyme 2 & ACE2 & 10 & 1.72 & 0.006 \\
\hline epidermal retinol dehydrogenase 2 & SDR16C5 & 3 & 1.74 & 0.042 \\
\hline PREDICTED: liver carboxylesterase 1-like & CES1 & 3 & 1.77 & 0.029 \\
\hline PREDICTED: serpin B6 isoform 7 & SERPINB6 & 2 & 1.83 & 0.019 \\
\hline macrophage-capping protein & CAPG & 7 & 1.84 & 0.017 \\
\hline hypothetical protein EGK_08282, partial & MFAP4 & 7 & 1.89 & 0.003 \\
\hline calponin-1 & CNN1 & 10 & 2.01 & 0.000 \\
\hline hypothetical protein EGK_10576 & LGALS7 & 6 & 2.02 & 0.000 \\
\hline $\begin{array}{l}\text { PREDICTED: SID1 transmembrane family member } 2 \\
\text { isoform } 2\end{array}$ & SIDT2 & 17 & 2.06 & 0.000 \\
\hline prolargin precursor & PRELP & 13 & 2.14 & 0.000 \\
\hline hexokinase-2 & HK2 & 6 & 2.17 & 0.012 \\
\hline mimecan precursor & OGN & 10 & 2.21 & 0.000 \\
\hline lumican precursor & LUM & 18 & 2.35 & 0.000 \\
\hline PREDICTED: collagen alpha-1(XII) chain-like & COL12A1 & 2 & 2.64 & 0.013 \\
\hline fibromodulin precursor & FMOD & 3 & 2.81 & 0.023 \\
\hline biglycan preproprotein & BGN & 15 & 3.22 & 0.000 \\
\hline
\end{tabular}

the early and recovery stages of heat induced testicular damage in men, by using two-dimensional SDS-PAGE and mass spectrometry (2DE-MS), and found 32 and 26 differentially expressed proteins at week 2 and week 9 after heat treatment, when taking a 1.2-fold change as a standard. However, our study identified more differentially expressed proteins, especially at the early stage of damage. It is worth noting that the standard in our study was 1.5 -fold change. It was difficult to compare the enriched pathways between that study and ours, since the 
Table 3: List of differentially expressed proteins on monkey testis collected at day 60 post-treatment compared with pre-treatment

\begin{tabular}{|c|c|c|c|c|}
\hline Protein & Gene & Peptides & Fold change & p-value \\
\hline Histone $\mathrm{H} 2 \mathrm{~B}$, testis & HIST1H2BA & 8 & 0.60 & 0.021 \\
\hline PREDICTED: 60S ribosomal protein L18a-like isoform 2 & RPL18A & 2 & 1.51 & 0.038 \\
\hline hypothetical protein EGK_18625 & IGHM & 5 & 1.51 & 0.008 \\
\hline decorin isoform a preproprotein & $\mathrm{DCN}$ & 13 & 1.52 & 0.000 \\
\hline keratin, type II cytoskeletal 8 & KRT8 & 13 & 1.52 & 0.000 \\
\hline Olfactomedin-like protein 1 & OLFML1 & 8 & 1.53 & 0.003 \\
\hline hypothetical protein EGK_17543 & ANXA2 & 27 & 1.53 & 0.000 \\
\hline galectin-1 & LGALS1 & 10 & 1.56 & 0.000 \\
\hline hypothetical protein EGK_10576 & LGALS7 & 6 & 1.58 & 0.001 \\
\hline cochlin precursor & $\mathrm{COCH}$ & 2 & 1.59 & 0.022 \\
\hline thioredoxin & $\mathrm{TXN}$ & 6 & 1.59 & 0.004 \\
\hline hemoglobin subunit beta & HBB & 27 & 1.59 & 0.000 \\
\hline Coagulation factor XIII A chain & F13A1 & 6 & 1.63 & 0.006 \\
\hline PREDICTED: annexin A1 isoform 4 & ANXA1 & 18 & 1.64 & 0.001 \\
\hline hypothetical protein EGK_01534 & APOA2 & 5 & 1.64 & 0.004 \\
\hline Putative thymosin beta-4-like protein 1, partial & TMSB4X & 2 & 1.64 & 0.015 \\
\hline carbonic anhydrase 2 & CA2 & 9 & 1.68 & 0.000 \\
\hline hypothetical protein EGK_04859 & COL4A3 & 4 & 1.68 & 0.033 \\
\hline prolargin precursor & PRELP & 13 & 1.75 & 0.008 \\
\hline lumican precursor & LUM & 18 & 1.97 & 0.000 \\
\hline protein S100-A6 & S100A6 & 4 & 2.05 & 0.015 \\
\hline immunoglobulin heavy chain & IGHG1 & 20 & 2.12 & 0.000 \\
\hline biglycan preproprotein & $\mathrm{BGN}$ & 15 & 2.22 & 0.000 \\
\hline hypothetical protein EGK_08282, partial & MFAP4 & 7 & 2.38 & 0.000 \\
\hline
\end{tabular}

bioinformatics analysis between these two studies were different. Nevertheless, both studies enriched spliceosome as one the most significant pathways at the early stage of spermatogenic impairment. In that study, the investigators found that heat stress-induced alteration of heterogeneous nuclear ribonucleoprotein (hnRNP) expression was closely related to germ cell apoptosis [11]. In this study, we found that spliceosome was associated with seven differentially expressed proteins (HNRNPA3, HSPA2, TRA2B, ALYREF, HNRNPC, SRSF2, HNRNPK). The spliceosome is a conserved, very large complex that consists of five small nuclear ribonucleoprotein ( $\mathrm{snRNP}$ ) complexes (U1, U2, U4, U5, and U6) and approximately 150 proteins [19]. The spliceosome removes introns from a transcribed pre-mRNA and thus plays an important role in gene expression $[20,21]$. Studies have shown that the spliceosome is also critical in normal spermatogenesis. As a component of the spliceosome, U2A loss in germ cells of Drosophila testes caused insufficient splicing of mRNAs required for the transition of germ cells from proliferation to differentiation, resulting in the accumulation of mitotic spermatogonia that failed to differentiate into spermatocytes and mature sperm [22]. Alikhani et al. [23] carried out a proteomic analysis on testicular tissue specimens and found that RNA splicing was one of the most significantly altered biological processes in patients with Sertoli cell-only syndrome. Heat exposure altered the expression of some protein components of the spliceosome 
and resulted in dysfunction of RNA splicing in its target pre-mRNAs. This process may be critical in heat-induced germ cell apoptosis.

Our proteomic analysis also revealed some protein targets and pathways which played important roles in germ cell apoptosis. Heat shock-related $70 \mathrm{kDa}$ protein 2 (HSPA2) and SHC binding and spindle associated 1 like (SHCBP1L) were identified proteins with 0.52 and 0.53 -fold change of expression, respectively in our proteomic analysis. Studies showed that SHCBP1L binded to HSPA2, and maintained stability of the spindle [24](a). Both HSPA2 and SHCBP1L gene defencicy led to germ cell apoptosis [24, 25]. Protein processing in endoplasmic reticulum was enriched as another significant pathway, indicating that heat stress affected the function of endoplasmic reticulum. It is known that endoplasmic reticulum (ER) dysfunction would lead to ER stress, which is closely related to cell apoptosis $[26,27]$. Some other metabolism-related pathways like glucolysis/gluconeogenesis, cysteine and methionine metabolism as well as pyruvate metabolism were also enriched as significant pathways during the early stage of testicular damage. These altered metabolism status may also involved in the heat stress-induced spermatogenic impairment.

PSIP1, CIRBP, Sam68, and decorin were selected for validation for the iTRAQ data. Both immunohistochemical analysis and western blotting results were consistent with the iTRAQ results, indicating the reliability of the sample pooling strategy in the proteomic approach. CIRBP is an RNA-binding protein that participates in forming ribonucleoprotein complexes [28]. Nishiyama et al. [29] found the that CIRBP expression was down-regulated at elevated temperatures in germ cells of male mice and humans. Masuda et al. [30] investigated the function of CIRBP using a gene knockout model and showed that a Cirbp gene defect obviously suppressed the proliferation of undifferentiated spermatogonia. PSIP1, another RNA binding protein, was expressed in spermatocytes and spermatids. It has been reported that PSIP1 is closely involved in spermatomiosis [31]. Sam68 has also been
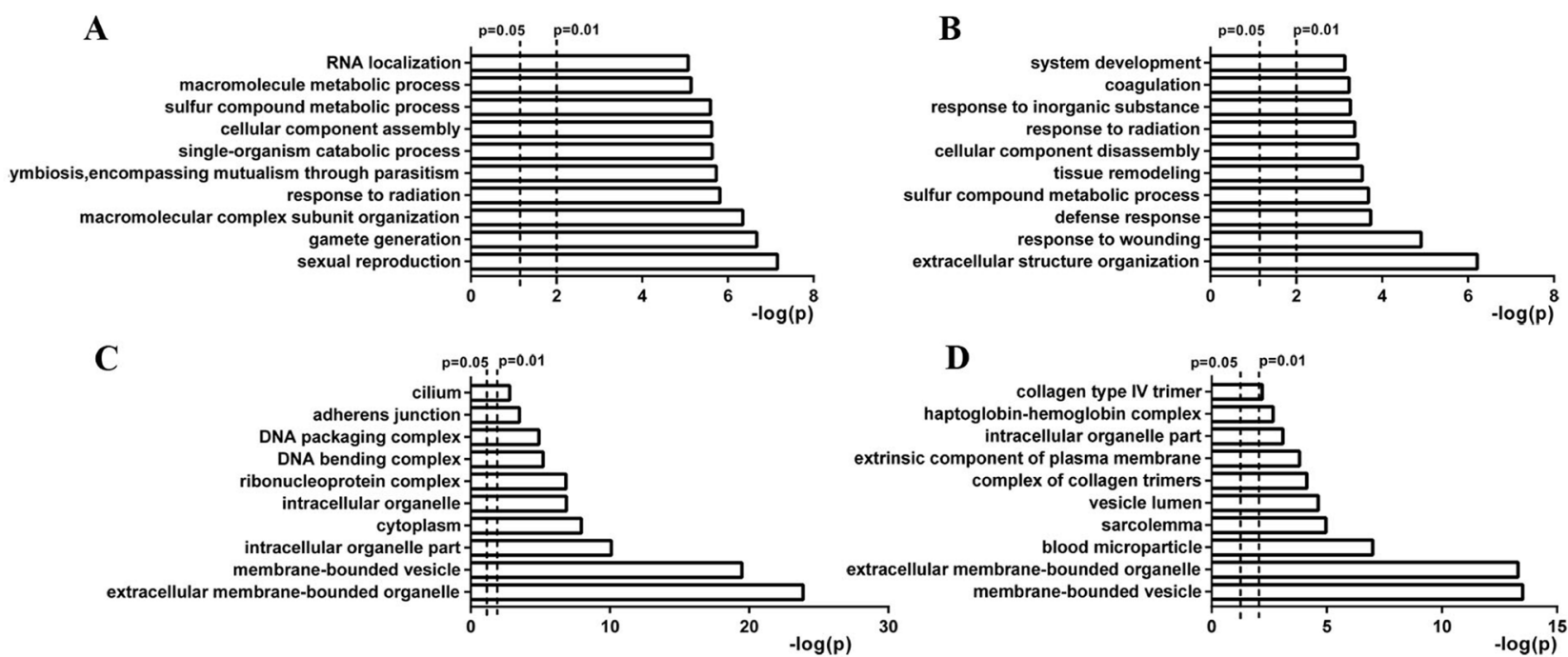

D

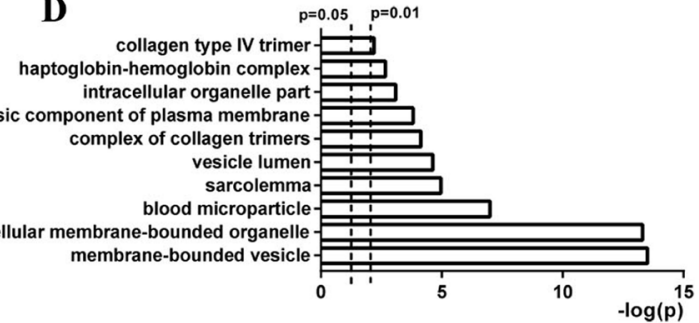

$\mathbf{E}$
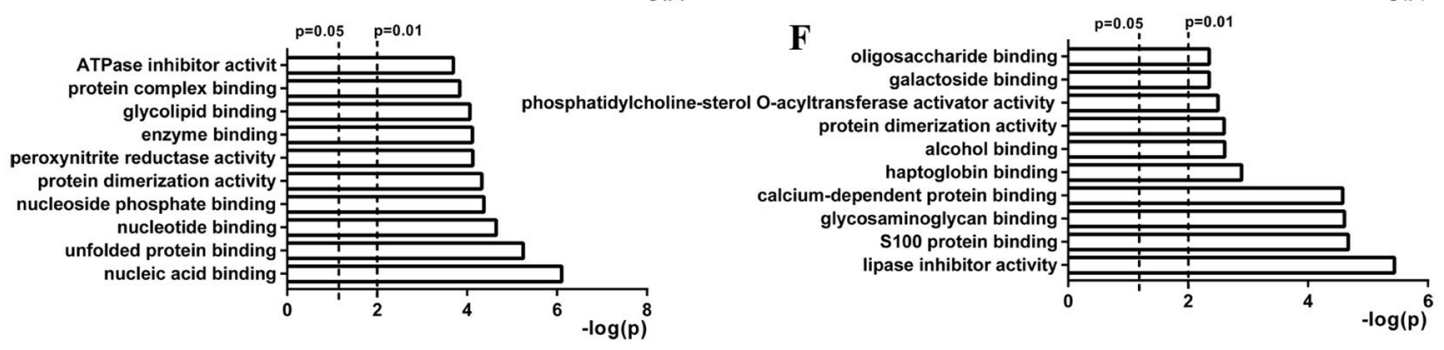

Figure 3: Gene ontology of differentially expressed proteins identified at days 8 and 60 after scrotal hyperthermia. Biological process (BP), cell component (CC), and molecular function (MF) are three basic information units of GO analysis. (A and B) show the top 10 significant BPs enriched for differentially expressed proteins identified at days 8 and 60 , respectively. (C and $\mathbf{D})$ show the top 10 significant CCs enriched for differentially expressed proteins identified at days 8 and 60, respectively. (E and $\mathbf{F})$ show the top 10 significant MFs enriched for differentially expressed proteins identified at days 8 and 60, respectively. 
Table 4: KEGG pathways enriched for altered proteins identified from day 8 testis tissues compared with pretreatment

\begin{tabular}{|c|c|c|c|}
\hline Pathway Name & Pathway ID & Genes & p-value \\
\hline Spliceosome & hsa03040 & $\begin{array}{l}\text { HNRNPA3, HSPA2, TRA2B, ALYREF, } \\
\text { HNRNPC, SRSF2, HNRNPK }\end{array}$ & $3.36 \mathrm{E}-05$ \\
\hline Estrogen signaling pathway & hsa04915 & $\begin{array}{c}\text { GNAQ, HSP90AA1, HSPA2, AKT1, } \\
\text { CALM1 }\end{array}$ & $6.68 \mathrm{E}-04$ \\
\hline Pyruvate metabolism & hsa00620 & LDHC, ACYP1, LDHAL6B & $2.98 \mathrm{E}-03$ \\
\hline $\begin{array}{l}\text { Adrenergic signaling in } \\
\text { cardiomyocytes }\end{array}$ & hsa04261 & GNAQ, AKT1, TPM1, TPM2, CALM1 & $3.91 \mathrm{E}-03$ \\
\hline Glycolysis / Gluconeogenesis & hsa00010 & LDHC, LDHAL6B, HK2 & $1.13 \mathrm{E}-02$ \\
\hline Systemic lupus erythematosus & hsa05322 & HIST1H2BA, H2AFX, HIST1H2AG, C9 & $1.63 \mathrm{E}-02$ \\
\hline Propanoate metabolism & hsa00640 & LDHC, LDHAL6B & $2.15 \mathrm{E}-02$ \\
\hline $\begin{array}{l}\text { Cysteine and methionine } \\
\text { metabolism }\end{array}$ & hsa00270 & LDHC, LDHAL6B & $2.82 \mathrm{E}-02$ \\
\hline $\begin{array}{l}\text { Protein processing in endoplasmic } \\
\text { reticulum }\end{array}$ & hsa04141 & HSP90AA1, HSPA2, HSPA4L, UBQLN3 & $3.08 \mathrm{E}-02$ \\
\hline $\begin{array}{l}\text { Butirosin and neomycin } \\
\text { biosynthesis }\end{array}$ & hsa00524 & HK2 & $3.51 \mathrm{E}-02$ \\
\hline Alcoholism & hsa05034 & $\begin{array}{c}\text { HIST1H2BA, H2AFX, HIST1H2AG } \\
\text { CALM1 }\end{array}$ & $3.83 \mathrm{E}-02$ \\
\hline $\begin{array}{l}\text { Carbohydrate digestion and } \\
\text { absorption }\end{array}$ & hsa04973 & AKT1, HK2 & 4.04E-02 \\
\hline Amoebiasis & hsa05146 & GNAQ, C9, SERPINB6 & $4.20 \mathrm{E}-02$ \\
\hline $\begin{array}{l}\text { Amino sugar and nucleotide sugar } \\
\text { metabolism }\end{array}$ & hsa00520 & HEXA, HK2 & $4.37 \mathrm{E}-02$ \\
\hline
\end{tabular}

Table 5: KEGG pathways enriched for altered proteins identified from day 60 testis tissues compared with pre-treatment

\begin{tabular}{lccc}
\hline Pathway Name & Pathway ID & Genes & p-value \\
\hline Nitrogen metabolism & hsa00910 & CA2 & $2.49 \mathrm{E}-02$ \\
$\begin{array}{l}\text { Proximal tubule bicarbonate } \\
\text { reclamation }\end{array}$ & hsa04964 & CA2 & $3.36 \mathrm{E}-02$ \\
Collecting duct acid secretion & hsa04966 & CA2 & $3.93 \mathrm{E}-02$ \\
Proteoglycans in cancer & hsa05205 & LUM, DCN & $4.18 \mathrm{E}-02$ \\
African trypanosomiasis & hsa05143 & HBB & $4.93 \mathrm{E}-02$ \\
\hline
\end{tabular}

found to be closely related to spermatogenesis and plays an important role in regulating the expression of meiosis-related genes [32, 33]. A lack of Sam68 was found to cause decreased production of spermatozoa, which also displayed dramatic motility defects and were unable to fertilize eggs [33]. Li et al. [34] found a Sam68 expression deficiency in human testes, with maturation arrest at the spermatocyte stage and Sertoli cell-only syndrome in comparison with normal spermatogenesis. Furthermore, decreased expression of Sam68 suppressed germ cell proliferation and induced apoptosis in transfected GC-2spd cells. Decorin in the 

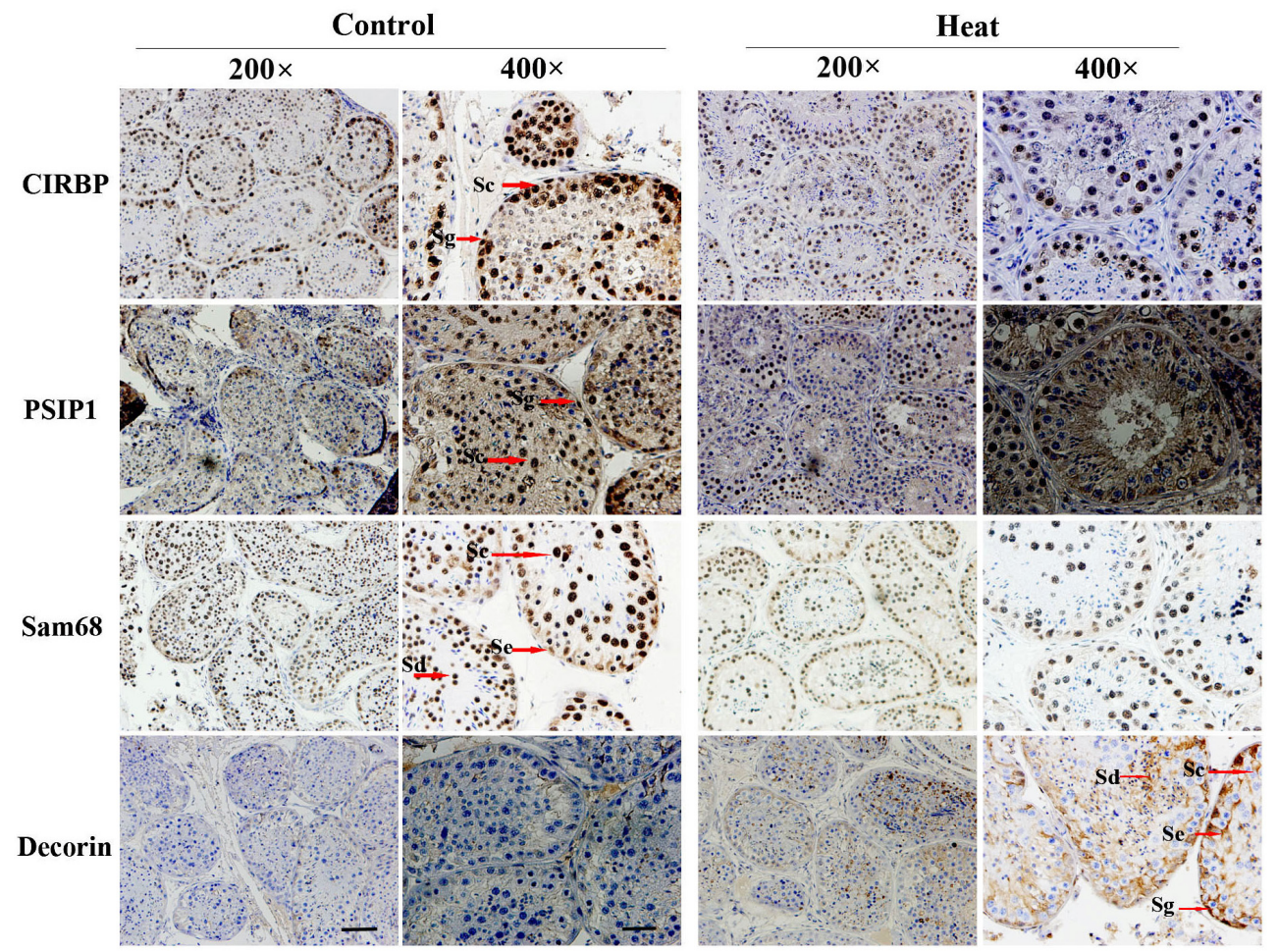

Figure 4: Immunohistochemical staining of CIRBP, PSIP1, Sam68, and Decorin on monkey testis. Two representative pictures $(200 \times$ and $400 \times)$ are shown for each marker. Sc, spermatocyte; Sg, spermatogonia; Se, Sertoli cells; Sd, spermatid; Pb, peritubular cell. For $200 \times$ images, scale bar $=50 \mu \mathrm{m}$; for $400 \times$ images, scale bar $=25 \mu \mathrm{m}$.
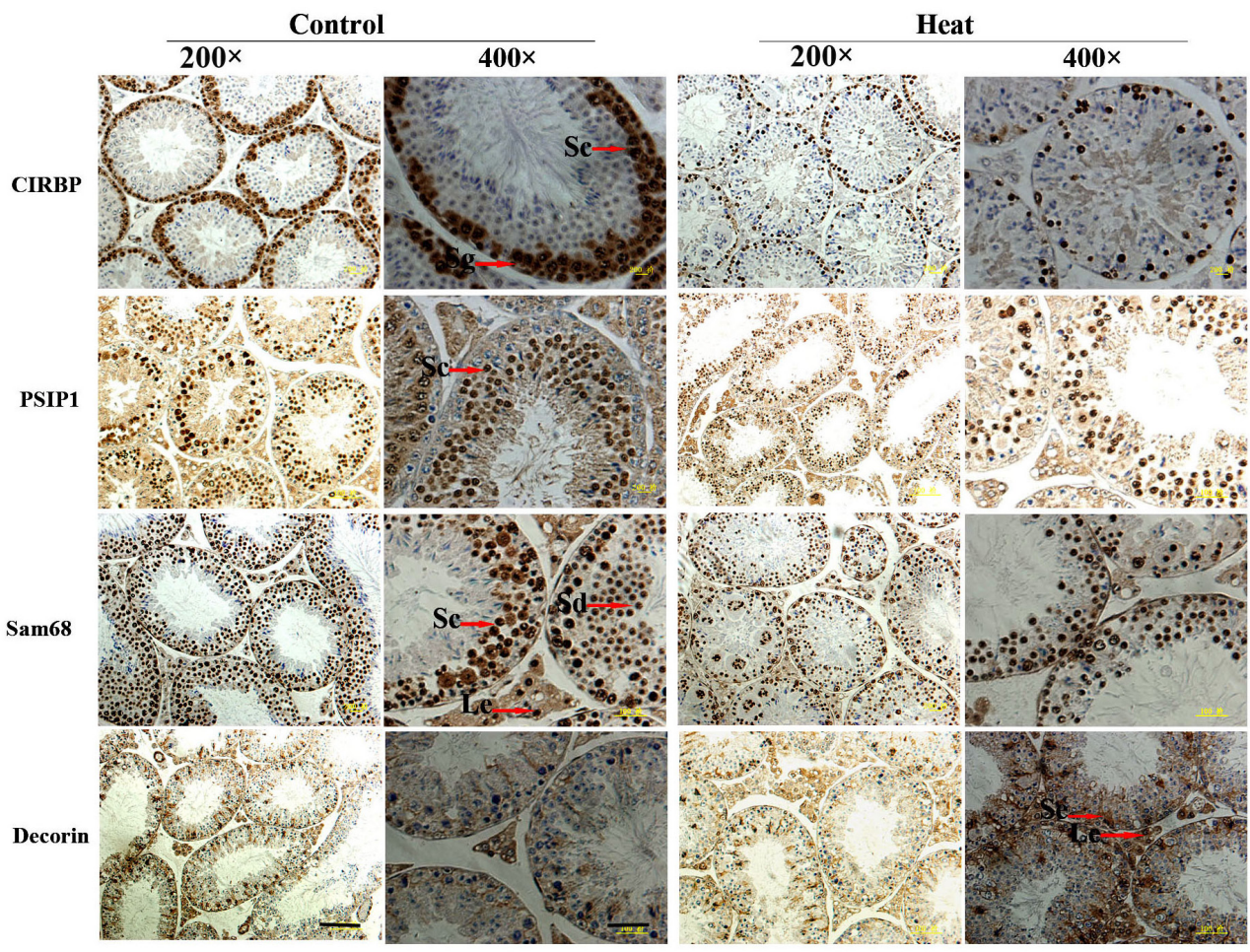

Figure 5: Immunohistochemical staining of CIRBP, PSIP1, Sam68, and Decorin on mouse testis. Two representative pictures $(100 \times$ and $400 \times)$ are shown for each marker. Sc, spermatocyte; Sg, spermatogonia; Se, Sertoli cells; Sd, spermatid; Le, Leydig cell; $\mathrm{Pb}$, peritubular cell. For $200 \times$ images, scale bar $=50 \mu \mathrm{m}$; for $400 \times$ images, scale bar $=25 \mu \mathrm{m}$ 
testis is mainly produced by myofibroblastic peritubular cells in the walls of seminiferous tubules [35, 36]. Adam et al. [35] reported an increased concentration of testicular decorin in infertile men, and the increase in decorin may consequently imbalance the paracrine signaling pathways in human testes, which has also been demonstrated in mice and monkeys [36]. It is worthy of note that only four of the differentially expressed proteins were selected for validation of the $\mathrm{iTRAQ}$ results; other proteins may also be very important molecular targets involved in heat-induced spermatogenic impairment.

In summary, this study investigated the testicular proteomic profiles of monkeys exposed to transient scrotal hyperthermia. A total of 101 and 24 proteins were found to be differentially expressed at the early and recovery stages of testicular damage respectively, when compared to pretreatment. Most of the identified and differentially regulated proteins at the early stage of damage can be divided into the following categories according to their molecular functions: nucleotide binding, and nucleoside phosphate binding, unfolded protein binding, nucleotide binding, and nucleoside phosphate binding. The most significant pathway for these differentially expressed proteins at the early stage of damage was the spliceosome, with seven proteins involved. CIRBP, PSIP1, Sam68, and decorin were validated and found to be consistent with the proteomic data, indicating the reliability of the proteomic profiles identified in this study. We suggest that the proteins identified in this study play important roles in heatinduced spermatogenic impairment. Further study is required to clarify the roles of these molecular targets in the pathogenesis of heat-induced male infertility.

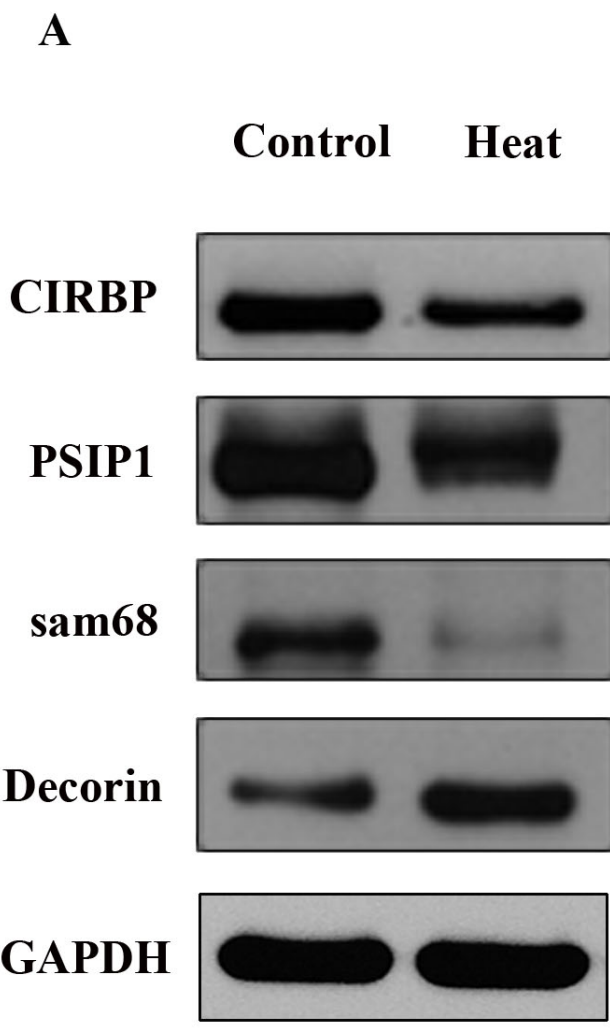

18 KDa
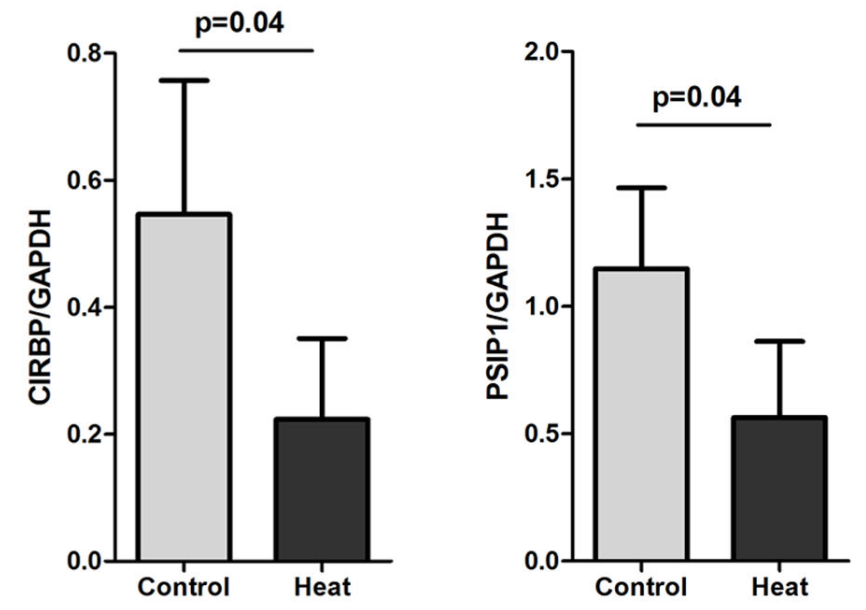

$60 \mathrm{KDa}$
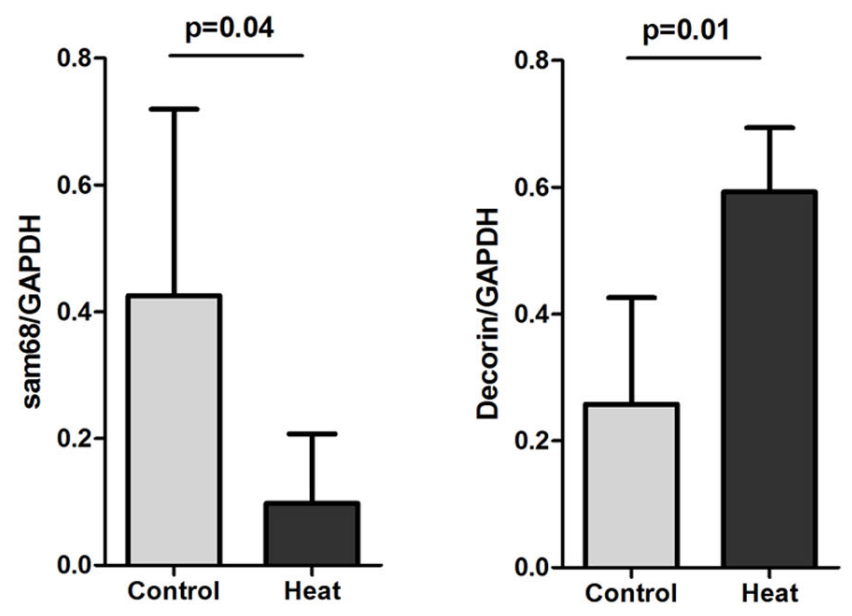

Figure 6: Western blotting results of CIRBP, PSIP1, Sam68, and Decorin on monkey testis analyzed before scrotal hyperthermia and at day 8 after the beginning of hyperthermia. For each time point, $n=4$. 


\section{MATERIALS AND METHODS}

\section{Animals and study design}

This study was approved by the Animal Care and Use Committee at Fujian provincial Population and Family Planning Research Institute. Eight male adult ( 8 to 10 years old) rhesus monkeys were obtained and housed at the Fuzhou Primate Research Center, Family Planning Research Institute of Fujian Province. The monkeys were housed in a standard animal facility under controlled temperature $\left(22^{\circ} \mathrm{C}\right)$ and photoperiod $(12 \mathrm{~h}$ of light and $12 \mathrm{~h}$ of darkness) with free access to water and food. All monkeys were subjected to scrotal hyperthermia at $43^{\circ} \mathrm{C}$ for 30 min once daily for 6 consecutive days, as previously described [16]. In brief, after monkeys were anesthetized with an intramuscular injection of ketamine ( 5 to $10 \mathrm{mg} / \mathrm{kg}$ body weight), their scrota were immersed in a thermostatically controlled water bath at $43^{\circ} \mathrm{C}$ for $30 \mathrm{~min}$. After heat treatment, the animals were dried, examined for any injury to the testes, and returned to their cages. No injuries to the monkeys' scrotal skin were found during this process.

Semen samples, blood, and testes biopsy tissues were collected 2 weeks before scrotal hyperthermia and at days $8,15,30,45,60,75$, and 90 after the beginning of hyperthermia. To avoid damage from frequent biopsies to the testes, the eight monkeys were randomly divided into two groups, four monkeys in each group. Biopsies were taken alternately from the two groups and also from testes on alternate sides. Thus, for each animal, two biopsies were taken from the left testis and another two from the right testis.

\section{Semen collection and analysis}

Semen samples were collected using an electronic stimulator provided by the Fuzhou Primate Research Center (self-made). A stimulus was produced when the alternating current sine wave pulse went through a ring electrode. After the monkeys were anesthetized with an intramuscular injection of ketamine $(5 \mathrm{mg} / \mathrm{kg}$ body weight), the stimulator was lubricated and inserted into the anus to about $9 \mathrm{~cm}$. The stimulator was then electrified every 5 seconds. The penis became erect to ejaculate as the voltage increased from $1.3 \mathrm{~V} \rightarrow 2.1 \mathrm{~V} \rightarrow 3.6 \mathrm{~V} \rightarrow 7.2 \mathrm{~V} \rightarrow 8.6 \mathrm{~V}$. Each ejaculate included both fluid and coagulum fractions. The sperm concentration and motility were determined from the fluid fraction using a hemocytometer and expressed as $\times 10^{6} / \mathrm{ml}$. Both progressive sperm motility and total sperm motility were examined. Semen samples from three monkeys were collected and analyzed at each time point.

\section{Blood collection and hormone assay}

Blood samples were collected from an arm vein while the monkeys were briefly restrained, and serum was separated and stored at $-80^{\circ} \mathrm{C}$ for subsequent assays of follicle stimulating hormone (FSH), luteinizing hormone (LH), and total testosterone (TT) using enzyme-linked immunosorbent assay with kits provided by Cusabio Biotech (Wuhan, China). The lower limits of quantitation for FSH, LH, and TT were $0.2 \mathrm{mIU} / \mathrm{ml}, 0.5 \mathrm{mIU} / \mathrm{ml}$, and $0.05 \mathrm{ng} / \mathrm{ml}$, respectively. The intra-assay and inter-assay coefficients of variation for these three parameters were all less than $15 \%$.

\section{Testicular biopsy and morphological observation}

Open testicular biopsies were performed under aseptic conditions, after the monkeys had been anesthetized with ketamine (10 mg/kg body weight). Testicular tissues from each monkey were divided into three samples. One sample was fixed in Bouin's solution immediately for morphological observation, and the remainder was stored at $-80^{\circ} \mathrm{C}$ for gene and protein analysis. Morphological evaluation was performed with hematoxylin and eosin (HE) staining. Briefly, sections from paraffin-embedded tissues were dewaxed in xylene, hydrated through a graded series of decreasing concentrations of alcohol, and stained with hematoxylin and eosin separately. After washing, the slides were dehydrated through a series of graded alcohols and xylene and mounted with neutral resin. Testicular histology was evaluated by quantifying the diameter of seminiferous tubules and the thickness of germinal epithelium as described in other studies [37, 38] Briefly, 30 transverse sections of seminiferous tubules from each slide were randomly selected. Diameter of each tubule was measured across the minor axe of its profile with an ocular micrometer calibrated by a stage micrometer. Thickness of germinal epithelium was quantified by measuring the distance from the lumen to the basement membrane. The average value from those 30 tubules were regarded as the value of one specific animal, 4 animals were analyzed at each time point.

\section{iTRAQ analysis}

\section{Protein extraction and preparation}

Testicular tissues collected before scrotal hyperthermia (day 0 ) and at days 8,30 , and 60 after hyperthermia were used for iTRAQ analysis. Four tissue samples $(30 \mathrm{mg})$ from each time point were pooled separately. The pooled samples were ground to powder with liquid nitrogen and dissolved in a lysis solution (9 mol/L urea, 4\% CHAPS, $1 \%$ IPG buffer, $1 \%$ DTT) at $30^{\circ} \mathrm{C}$ for $1 \mathrm{~h}$. Following two centrifugations at $15,000 \mathrm{~g}$ for $15 \mathrm{~min}$ at room temperature, the supernatant was collected and the concentrations of the protein extracts were determined by the Bradford method [39]. A sample of $100 \mu \mathrm{g}$ protein from each pooled sample was used for iTRAQ labeling according to the manufacturer's protocol (ABI System, USA). Briefly, five volumes of cold acetone 
were added to each sample tube, vortexed and then held at $-20^{\circ} \mathrm{C}$ for $1 \mathrm{~h}$. After centrifugation at $12,000 \mathrm{rpm}$ for $15 \mathrm{~min}$ at $4^{\circ} \mathrm{C}$, the deposit was collected and dried in a vacuum freeze dryer. Then $50 \mu$ dissolution buffer and $4 \mu \mathrm{l}$ reducing reagent were added to the deposit and incubated at $60^{\circ} \mathrm{C}$ for $1 \mathrm{~h}$. Following incubation with 2 $\mu \mathrm{l}$ cysteine-blocking reagents at room temperature for 10 min, the solution was cleaned with a $10-\mathrm{KDa}$ ultrafiltration tube and centrifuged at 12,000 rpm for $20 \mathrm{~min}$. Next, 100 $\mu \mathrm{l}$ dissolution buffer was added to wash the proteins at $12,000 \mathrm{rpm}$ three times for $15 \mathrm{~min}$. After washing, $50 \mu \mathrm{l}$ trypsin $(50 \mathrm{ng} / \mu \mathrm{l})$ was added and incubated at $37^{\circ} \mathrm{C}$ for $12 \mathrm{~h}$ to digest each sample. After centrifugation at 12,000 rpm for $20 \mathrm{~min}$ to collect the peptides, the filter unit was transferred to a new collection tube and $50 \mu$ dissolution buffer was added to centrifuge again, and the two filter solutions were combined for protein labeling.

\section{Protein labeling and MS analysis}

Each iTRAQ reagent was brought to room temperature and spun down to bring the solution to the bottom of the tube before use. Each iTRAQ reagent was dissolved in $150 \mu \mathrm{l}$ of ethanol, then this reagent was added to $50 \mu \mathrm{l}$ samples $(100 \mu \mathrm{g}$ peptide) and incubated at room temperature for $2 \mathrm{~h}$, after which $100 \mu \mathrm{l}$ of Milli-Q water was added to stop the labeling reaction. Then, $1 \mu$ l content of each iTRAQ reagent-labeled sample was pooled, cleaned up using a Ziptip, and tested by MALDI-TOF/ TOF analysis to ensure the effect of labeling. The samples were pooled, spun, and dried in a vacuum freeze dryer for iTRAQ analysis.

\section{Strong cation exchange (SCX) analysis}

Sample fractionation was performed by strong cation exchange (SCX) chromatography on the Agilent 1200 HPLC System. The HPLC column was from Michrom. The parameters were Poly-SEA $5 \mu 300 \AA 2.0$ $\times 150 \mathrm{~mm}$, flow rate $0.5 \mathrm{ml} / \mathrm{min}$ with $215 \mathrm{~nm}$ and $280 \mathrm{~nm}$ UV detection. In brief, the dry sample was re-suspended with $100 \mu \mathrm{l}$ SCX buffer A (10 mM formic acid, 20\% acetonitrile), fractionated, and collected as 12 fractions. The first fraction was collected from 0 to $5 \mathrm{~min}$, another 10 fractions were collected from 6 to 44 min at intervals of $4 \mathrm{~min}$, and the final fraction was collected from 45 to $50 \mathrm{~min}$. Each fraction was dried in a vacuum freeze dryer for LC-MS/MS analysis.

\section{Reversed-phase nanoliquid chromatography- tandem MS (RPLC-MS/MS) analysis}

Online Nano-RPLC was used on an Eksigent nanoLC-Ultra ${ }^{\text {TM }}$ 2D System (AB SCIEX). The samples were re-suspended with Nano-RPLC buffer A $(0.1 \%$ formic acid, $2 \%$ acetonitrile), loaded on a $\mathrm{C} 18$ nanoLC trap column $(100 \mu \mathrm{m} \times 3 \mathrm{~cm}, \mathrm{C} 18,3-\mu \mathrm{m}$ particle size, $150 \AA$ ), and washed with Nano-RPLC buffer $\mathrm{A}$ at a flow rate of $2 \mu \mathrm{l} / \mathrm{min}$ for $10 \mathrm{~min}$. A linear LC gradient profile was used to elute peptides from the analytical ChromXP C18 column $(75 \mu \mathrm{m} \times 15 \mathrm{~cm}, \mathrm{C} 18,3-\mu \mathrm{m}$ particle size, 120 $\AA$, Eksigent). The gradient began with 5\% Nano-RPLC buffer B ( $0.1 \%$ formic acid, $98 \%$ acetonitrile) and rose to $35 \%$ within $70 \mathrm{~min}$. Data acquisition was performed with a Triple TOF 5600 System (AB SCIEX, USA) fitted with a Nanospray III source (AB SCIEX, USA) and a pulled quartz tip as the emitter (New Objectives, USA). Data were acquired using an ion spray voltage of $2.5 \mathrm{kV}$, curtain gas of 30 PSI, nebulizer gas of 5 PSI, and an interface heater temperature of $150^{\circ} \mathrm{C}$. For information dependent acquisition, survey scans were acquired in $250 \mathrm{~ms}$, and as many as 35 product ion scans were collected if they exceeded a threshold of 150 counts per second (counts/s) with a $2+$ to $5+$ charge-state. The total cycle time was fixed to $2.5 \mathrm{~s}$. A rolling collision energy setting was applied to all precursor ions for collision-induced dissociation.

\section{Protein identification and quantification}

Data was processed with ProteinPilot v.4.5 (AB SCIEX, USA) and a Macaca mulatta database using the Paragon algorithm [40]. Protein identification was performed with the search option "emphasis on biological modifications." The database search parameters were as follows: the instrument was TripleTOF 5600, iTRAQ 4-plex quantification, cysteine modified with iodoacetamide, biological modifications as the ID focus, trypsin digestion. An automatic decoy database search strategy was used to estimate the false discovery rate (FDR) using PSPEP (Proteomics System Performance Evaluation Pipeline) software, integrated with ProteinPilot. The FDR was calculated as the falsepositive matches divided by the total matches. The iTRAQ 4-plex was chosen for protein quantification with unique peptides during the search. A total of 3789 proteins were identified and considered for further analysis. Proteins with corrected average fold changes of $>1.50$ or $<0.67$ and $p<0.05$ were considered to be significantly differentially expressed.

\section{Mice scrotal heat treatment}

To validate whether the differentially expressed proteins identified by the iTRAQ analysis showed the same pattern of change in mice before and after heat stress, we induced mice scrotal hyperthermia, as described in another study [41]. Briefly, 10 male adult ICR mice (8 to 9 weeks old) were used; 5 were subjected to scrotal heat treatment at $43^{\circ} \mathrm{C}$ for $30 \mathrm{~min}$, and the other 5 were controls. All mice were anaesthetized with $1 \%$ pentobarbital sodium by intraperitoneal injection ( $50 \mathrm{mg} / \mathrm{kg}$ body weight). In the heat treatment group, the mice scrota were immersed 
in a thermostatically controlled water bath at $43^{\circ} \mathrm{C}$ for 30 min. The control mice were left at room temperature. After the heat treatment, the animals were dried and returned to their cages. The mice were sacrificed $12 \mathrm{~h}$ after heat treatment. One testis of each mouse was fixed in Bouin's solution for immunohistochemical examination, and the other testis was frozen in liquid nitrogen for western blot analysis.

\section{Western blotting}

From the differentially expressed proteins, we selected the proteins PC4 and SFRS1 interacting protein 1 (PSIP1), Src-associated substrate in mitosis of 68 $\mathrm{kDa}$ (Sam68), cold-inducible RNA-binding protein (CIRBP), and decorin for western blotting to validate their expression levels in the monkey testes before and after hyperthermia. It should be noted that the western blot analysis was based on four individual subjects, not pooled tissue samples. Samples containing $40 \mu \mathrm{g}$ total proteins were separated by $10 \%$ (PSIP1, Sam68, decorin) or $15 \%$ (CIRBP) SDS-PAGE. After transfer onto PVDF membranes by electroblotting, the proteins were then probed with the following primary antibodies: CIRBP polyclonal antibody (Abcam, ab106230, 1:1000 dilution), PSIP1 polyclonal antibody (Abcam, ab70641, 1:500 dilution), Sam68 polyclonal antibody (Abcam, ab86239, 1:1000 dilution), decorin polyclonal antibody (Abcam, ab35378, 1:1000 dilution), and GAPDH polyclonal antibody (Abcam, ab37168, 1:10000 dilution). After washing three times with TBST for $5 \mathrm{~min}$, the membranes were incubated with appropriate horseradish peroxidase conjugated goat anti-rabbit (KPL, 074-1506, 1:10000 dilution), rabbit anti-goat (KPL, 14-13-06, 1:10000), or rabbit anti-sheep (Aspen, AS-1114, 1:10000) secondary antibodies. Specific proteins were detected using an ECL kit (Aspen) and exposed to film. The protein expression level was analyzed by AlphaEaseFC software (Alpha Innotech) and the data were normalized using GAPDH. $\mathrm{N}=4$ at each time point.

\section{Immunohistochemical analysis}

Paraffin-embedded sections from the monkey and mouse testis tissue before and after heat stress were used for immunohistochemical analysis. Briefly, after dewaxing and hydration, sections were treated with $\mathrm{H}_{2} \mathrm{O}_{2}$ to quench the endogenous peroxidase activity, blocked using a blocking serum and then incubated overnight at $4^{\circ} \mathrm{C}$ with primary antibodies to PSIPS (1:100), CIRBP (1:50), Sam68 (1:100), and decorin (1:100). The sections were then incubated with HRP-conjugated secondary antibodies (KPL, 1:400). Immunostaining was developed with a diaminobenzidine kit and counterstained with hematoxylin, and the sections were then dehydrated and mounted.

\section{Statistical analysis}

Sperm parameters, reproductive hormones, and relative protein expression levels are presented as mean $\pm \mathrm{SD}$. Sperm parameters and reproductive hormones after hyperthermia were compared with the baseline levels by means of a paired non-parametric Wilcoxon test. Histological parameters (diameter of seminiferous tubules and thickness of germinal epithelium) evaluated at each time points were compared using one-way ANOVA and the LSD test. Relative protein expression levels before and after hyperthermia were compared using the MannWhitney U-test. Statistical analysis was performed with SPSS 17.0 software (SPSS Inc., Chicago, IL, USA); a $p$ level of less than 0.05 was considered to indicate statistical significance.

\section{Abbreviations}

iTRAQ: isobaric tags for relative and absolute quantification; LC-MS/MS: liquid chromatographytandem mass spectrometry; FDR: false discovery rate; GO: gene ontology; KEGG: Kyoto Encyclopedia of Genes and Genomes; PSIP1: PC4 and SFRS1 interacting protein 1; Sam68: Src-associated substrate in mitosis of $68 \mathrm{kDa}$; CIRBP: cold-inducible RNA-binding protein.

\section{Author contributions}

M.R., Y.Z., W.X. and C.Z. conceived and supervised the study. M.R., S.M. and S.H. performed the monkey heat stress experiment. H.L. and Y.W. performed the mice study. S.M and S.H. performed the statistical analysis. M.R. wrote the manuscript. W.X. and C.Z. revised the manuscript.

\section{ACKNOWLEDGMENTS}

This study was supported by the National Key Research and Development Program of China (No. 2016YFC1000903); the National Natural Science Foundation of China (No. 81671507); Independent Innovation funding of Huazhong University of Science and Technology (No. 2016YXMS164) and the Health and Family Planning Commission Program of Hubei Province (No. WJ2017M056). There are no competing interests. We wish to thank the laboratory staff from Fuzhou Primate Research Center for their help with the sperm and hormone analysis.

\section{CONFLICTS OF INTEREST}

The authors declare no conflicts of interest. 


\section{REFERENCES}

1. Ivell R. Lifestyle impact and the biology of the human scrotum. Reprod Biol Endocrinol. 2007; 5:15.

2. Liu Y, Li X. Molecular basis of cryptorchidism-induced infertility. Sci China Life Sci. 2010; 53:1274-1283.

3. Shiraishi K, Takihara H, Matsuyama H. Elevated scrotal temperature, but not varicocele grade, reflects testicular oxidative stress-mediated apoptosis. World J Urol. 2010; 28:359-364.

4. Thonneau P, Ducot B, Bujan L, Mieusset R, Spira A. Effect of male occupational heat exposure on time to pregnancy. Int J Androl. 1997; 20:274-278.

5. Hjollund NH, Bonde JP, Jensen TK, Olsen J, and The Danish First Pregnancy Planner Study Team. Diurnal scrotal skin temperature and semen quality. Int J Androl. 2000; 23:309-18.

6. Rao M, Xia W, Yang J, Hu LX, Hu SF, Lei H, Wu YQ, Zhu CH. Transient scrotal hyperthermia affects human sperm DNA integrity, sperm apoptosis, and sperm protein expression. Andrology. 2016; 4:1054-1063.

7. Rao M, Zhao XL, Yang J, Hu SF, Lei H, Xia W, Zhu $\mathrm{CH}$. Effect of transient scrotal hyperthermia on sperm parameters, seminal plasma biochemical markers, and oxidative stress in men. Asian J Androl. 2015; 17:668-675.

8. Hikim AP, Lue Y, Yamamoto CM, Vera Y, Rodriguez S, Yen PH, Soeng K, Wang C, Swerdloff RS. Key apoptotic pathways for heat-induced programmed germ cell death in the testis. Endocrinology. 2003; 144:3167-3175.

9. Vera Y, Diaz-Romero M, Rodriguez S, Lue Y, Wang C, Swerdloff RS, Sinha Hikim AP. Mitochondria-dependent pathway is involved in heat-induced male germ cell death: lessons from mutant mice. Biol Reprod. 2004; 70:1534-1540.

10. Rocha DR, Martins JA, van Tilburg MF, Oliveira RV, Moreno FB, Monteiro-Moreira AC, Moreira RA, Araujo AA, Moura AA. Effect of increased testicular temperature on seminal plasma proteome of the ram. Theriogenology. 2015; 84:1291-1305.

11. Zhu H, Cui Y, Xie J, Chen L, Chen X, Guo X, Zhu Y, Wang X, Tong J, Zhou Z, Jia Y, Lue YH, Hikim AS, et al. Proteomic analysis of testis biopsies in men treated with transient scrotal hyperthermia reveals the potential targets for contraceptive development. Proteomics. 2010; 10:3480-3493.

12. Zhu YF, Cui YG, Guo XJ, Wang L, Bi Y, Hu YQ, Zhao X, Liu Q, Huo R, Lin M, Zhou ZM, Sha JH. Proteomic analysis of effect of hyperthermia on spermatogenesis in adult male mice. J Proteome Res. 2006; 5:2217-2225.

13. Yu S, Cai X, Sun L, Zuo Z, Mipam T, Cao S, Shen L, Ren Z, Chen X, Yang F, Deng J, Ma X, Wang Y. Comparative iTRAQ proteomics revealed proteins associated with spermatogenic arrest of cattleyak. J Proteomics. 2016; 142:102-113.
14. Li G, Li M, Liang X, Xiao Z, Zhang P, Shao M, Peng F, Chen Y, Li Y, Chen Z. Identifying DCN and HSPD1 as Potential Biomarkers in Colon Cancer Using 2D-LC-MS/ MS Combined with iTRAQ Technology. J Cancer. 2017; 8:479-489.

15. Niu D, Sui J, Zhang J, Feng H, Chen WN. iTRAQ-coupled 2-D LC-MS/MS analysis of protein profile associated with HBV-modulated DNA methylation. Proteomics. 2009; 9:3856-3868.

16. Lue YH, Lasley BL, Laughlin LS, Swerdloff RS, Hikim AP, Leung A, Overstreet JW, Wang C. Mild testicular hyperthermia induces profound transitional spermatogenic suppression through increased germ cell apoptosis in adult cynomolgus monkeys (Macaca fascicularis). J Androl. 2002; 23:799-805.

17. Lue Y, Wang C, Liu YX, Hikim AP, Zhang XS, Ng CM, Hu ZY, Li YC, Leung A, Swerdloff RS. Transient testicular warming enhances the suppressive effect of testosterone on spermatogenesis in adult cynomolgus monkeys (Macaca fascicularis). J Clin Endocrinol Metab. 2006; 91:539-545.

18. Hou Y, Wang X, Lei Z, Ping J, Liu J, Ma Z, Zhang Z, Jia C, Jin M, Li X, Li X, Chen S, Lv Y, et al. Heat-stress-induced metabolic changes and altered male reproductive function. J Proteome Res. 2015; 14:1495-1503.

19. Wahl MC, Will CL, Luhrmann R. The spliceosome: design principles of a dynamic RNP machine. Cell. 2009; 136:701-718.

20. Gallego-Paez LM, Bordone MC, Leote AC, SaraivaAgostinho N, Ascensao-Ferreira M, Barbosa-Morais NL. Alternative splicing: the pledge, the turn, and the prestige : The key role of alternative splicing in human biological systems. Hum Genet. 2017; 136:1015-42. https:/doi. org/10.1007/s00439-017-1790-y.

21. Gault CM, Martin F, Mei W, Bai F, Black JB, Barbazuk WB, Settles AM. Aberrant splicing in maize rough endosperm 3 reveals a conserved role for U12 splicing in eukaryotic multicellular development. Proc Natl Acad Sci U S A. 2017; 114:E2195-E2204.

22. Wu H, Sun L, Wen Y, Liu Y, Yu J, Mao F, Wang Y, Tong C, Guo X, Hu Z, Sha J, Liu M, Xia L. Major spliceosome defects cause male infertility and are associated with nonobstructive azoospermia in humans. Proc Natl Acad Sci USA. 2016; 113:4134-4139.

23. Alikhani M, Mirzaei M, Sabbaghian M, Parsamatin P, Karamzadeh R, Adib S, Sodeifi N, Gilani MA, ZabetMoghaddam M, Parker L, Wu Y, Gupta V, Haynes PA, et al. Quantitative proteomic analysis of human testis reveals system-wide molecular and cellular pathways associated with non-obstructive azoospermia. J Proteomics. 2017; 162:141-54.

24. Liu M, Shi X, Bi Y, Qi L, Guo X, Wang L, Zhou Z, Sha J. SHCBP1L, a conserved protein in mammals, is predominantly expressed in male germ cells and maintains spindle stability during meiosis in testis. Mol Hum Reprod. 2014; 20:463-475. 
25. Widlak W, Vydra N, Malusecka E, Dudaladava V, Winiarski B, Scieglinska D, Widlak P. Heat shock transcription factor 1 down-regulates spermatocyte-specific $70 \mathrm{kDa}$ heat shock protein expression prior to the induction of apoptosis in mouse testes. Genes Cells. 2007; 12:487-499.

26. Ji YL, Wang Z, Wang H, Zhang C, Zhang Y, Zhao M, Chen $\mathrm{YH}$, Meng XH, Xu DX. Ascorbic acid protects against cadmium-induced endoplasmic reticulum stress and germ cell apoptosis in testes. Reprod Toxicol. 2012; 34:357-363.

27. Ji YL, Wang H, Zhang C, Zhang Y, Zhao M, Chen YH, Xu DX. N-acetylcysteine protects against cadmium-induced germ cell apoptosis by inhibiting endoplasmic reticulum stress in testes. Asian J Androl. 2013; 15:290-296.

28. Lunde BM, Moore C, Varani G. RNA-binding proteins: modular design for efficient function. Nat Rev Mol Cell Biol. 2007; 8:479-490.

29. Nishiyama H, Danno S, Kaneko Y, Itoh K, Yokoi H, Fukumoto M, Okuno H, Millan JL, Matsuda T, Yoshida O, Fujita J. Decreased expression of cold-inducible RNAbinding protein (CIRP) in male germ cells at elevated temperature. Am J Pathol. 1998; 152:289-296.

30. Masuda T, Itoh K, Higashitsuji H, Higashitsuji H, Nakazawa N, Sakurai T, Liu Y, Tokuchi H, Fujita T, Zhao Y, Nishiyama H, Tanaka T, Fukumoto M, et al. Coldinducible RNA-binding protein (Cirp) interacts with Dyrk1b/Mirk and promotes proliferation of immature male germ cells in mice. Proc Natl Acad Sci USA. 2012; 109:10885-10890.

31. Chapman KM, Powell HM, Chaudhary J, Shelton JM, Richardson JA, Richardson TE, Hamra FK. Linking spermatid ribonucleic acid (RNA) binding protein and retrogene diversity to reproductive success. Mol Cell Proteomics. 2013; 12:3221-3236.

32. Paronetto MP, Messina V, Barchi M, Geremia R, Richard S, Sette C. Sam68 marks the transcriptionally active stages of spermatogenesis and modulates alternative splicing in male germ cells. Nucleic Acids Res. 2011; 39:4961-4974.

33. Paronetto MP, Messina V, Bianchi E, Barchi M, Vogel G, Moretti C, Palombi F, Stefanini M, Geremia R, Richard S, Sette C. Sam68 regulates translation of target mRNAs in male germ cells, necessary for mouse spermatogenesis. J Cell Biol. 2009; 185:235-249.

34. Li LJ, Zhang FB, Liu SY, Tian YH, Le F, Lou HY, Huang HF, Jin F. Decreased expression of SAM68 in human testes with spermatogenic defects. Fertil Steril. 2014; 102:61-67 e63.

35. Adam M, Schwarzer JU, Kohn FM, Strauss L, Poutanen M, Mayerhofer A. Mast cell tryptase stimulates production of decorin by human testicular peritubular cells: possible role of decorin in male infertility by interfering with growth factor signaling. Hum Reprod. 2011; 26:2613-2625.

36. Adam M, Urbanski HF, Garyfallou VT, Welsch U, Kohn FM, Ullrich Schwarzer J, Strauss L, Poutanen M, Mayerhofer A. High levels of the extracellular matrix proteoglycan decorin are associated with inhibition of testicular function. Int J Androl. 2012; 35:550-561.

37. Wang C, Cui YG, Wang XH, Jia Y, Sinha Hikim A, Lue YH, Tong JS, Qian LX, Sha JH, Zhou ZM, Hull L, Leung A, Swerdloff RS. transient scrotal hyperthermia and levonorgestrel enhance testosterone-induced spermatogenesis suppression in men through increased germ cell apoptosis. J Clin Endocrinol Metab. 2007; 92:3292-3304.

38. Bakhtiary Z, Shahrooz R, Ahmadi A, Soltanalinejad F. Ethyl Pyruvate Ameliorates The Damage Induced by Cyclophosphamide on Adult Mice Testes. Int J Fertil Steril. 2016; 10:79-86.

39. Bradford MM. A rapid and sensitive method for the quantitation of microgram quantities of protein utilizing the principle of protein-dye binding. Anal Biochem. 1976; 72:248-254.

40. Shilov IV, Seymour SL, Patel AA, Loboda A, Tang WH, Keating SP, Hunter CL, Nuwaysir LM, Schaeffer DA. The Paragon Algorithm, a next generation search engine that uses sequence temperature values and feature probabilities to identify peptides from tandem mass spectra. Mol Cell Proteomics. 2007; 6:1638-1655.

41. Cai H, Ren Y, Li XX, Yang JL, Zhang CP, Chen M, Fan CH, $\mathrm{Hu}$ XQ, Hu ZY, Gao F, Liu YX. Scrotal heat stress causes a transient alteration in tight junctions and induction of TGFbeta expression. Int J Androl. 2011; 34:352-362. 